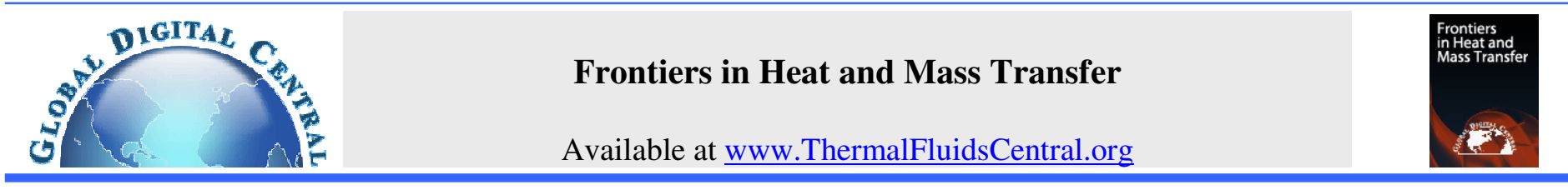

\title{
INFLUENCE OF CATTANEO-CHRISTOV HEAT FLUX MODEL ON MHD HYPERBOLIC TANGENT FLUID OVER A MOVING POROUS SURFACE
}

\author{
Z. Iqbal, Ehtsham Azhar*, E. N. Maraj and Bilal Ahmad \\ Department of Mathematics, HITEC University, Taxila, Pakistan
}

\begin{abstract}
Present investigation represent the study of Cattaneo-Christov heat flux model on boundary layer flow of hyperbolic tangent fluid which is generalized non-Newtonian fluid model over a continuously moving porous surface with a parallel free stream velocity. Mathematical formulation is completed in the presence of Magneto-hydrodynamics (MHD). Suitable relations transform the partial differential equations into the ordinary differential equations. Nonlinear flow analysis is computed and velocity and temperature profiles are obtained by shooting algorithm. Graphs are plotted to analyze the behavior of various involved physical parameters. Furthermore both type of flows Sakaidis ( $\lambda=1$ ) and Blasius flow $(0 \leq \lambda<1)$ are discussed significantly. Special emphasis has been given to flow patterns for both types of flows, presented through stream functions contour and 3D plots. Key finding includes: Boundary layer thickness is an increasing function of power law index $n$ and Suction parameter $s$ for the case of Blasius flow, opposite to Sakaidis flow and dwindle of thermal boundary layer is witness for rising values of $\gamma$, Pr and $S$, while augmented boundary layer is observed for increasing values of $n, M$ and fluid parameter.
\end{abstract}

Keywords: Three Cattaneo-Christov heat flux, Non-Newtonian fluid, Moving surface, Megnatohydrodynamics (MHD), Momentum transfer.

\section{INTRODUCTION}

This article investigates pseudo plastic fluids flow over a continuously moving surface taking into account Cattaneo-Christov heat flux. Applications of fluids flow on a moving surface are mostly encounter in polymer industries and many engineering processes such as cooling of polymer films or sheets, metallic plates on conveyers, filament disentangle incessantly from a die, long fiber travelling amid in feed roll and a wind up roll, etc. Sakiadis (1961) attempted to analyze boundary layer flow for an incompressible Newtonian fluid on an invariantly moving surface. He discovered that these types of flow problems leads to substantially different solutions compare to boundary layer flow on a stationary semi-infinite smooth shield examined by Blasius in (1908). Latterly, Pop in (1990) and (1992) highlighted some particular aspects of this flow.

It is well known that most of the fluids occurring in practical applications such as molten metal or plastics, polymers, pulps, food etc. have rheological characteristics of non-Newtonian fluids. Considerable effort has been directed towards understanding their friction and heat transfer characteristics because of the growing usage of such fluids. However, in chemical engineering researchers and scientist encounter inelastic non-Newtonian fluids known as power law fluids where shear varies to a power function of deformation rate. Tangent hyperbolic fluid discussed by Ali (2005) is among many other power law fluids which describe rheological behavior of pseudo plastic fluids. Harfoush et al. (1989) contributed by numerical investigation on analyzing electromagnetic wave scattering from moving surfaces in one and two dimensions. Grosan et al. (2000) carried out similarity solutions for boundary layer flow on a moving surface in non-Newtonian fluids. Elliott et al. (1983) explained breakdown of boundary layer in detail which turned to be a major contribution to the present dramatically growing applications of flow on a moving surface. The consequence of transpiration on self alike border line layer flow on moving surfaces was exploded by Weidman et al. (2006). Latterly, Bachok et al. (2010) inspected such flow of nanofluids in a flowing fluid.

Keeping the important of heat transfer in engineering procedures and industries, researchers and analyst are very keen in studying heat transfer attributes of different fluids in various flow problems. This phenomenon has been examined through established Fourier law of heat conduction (1822) till Cattaneo (1948) floated an adjustment in it by incorporating thermal relaxation effects. Christov (2008) upgraded his contribution by adding Oldroyd's upper convected derivatives. His modification is termed as Cattaneo-Christov heat flux model. Many researchers have examined the heat transfer of various fluids for different flow problems few are Han et al. (2014), Khan et al. (2015), Tibullo et al. (2011), Nadeem et al. (2016), Muhammad et al. (2017) and (2017), Li et al. (2016), Sui et al. (2016), Liu et al. (2017) and

* Corresponding author Email: ehtsham@uaar.edu.pk 
Mukhopadhyary (2009). To the best of author's knowledge up till now no one has attempted to study the heat transfer by taking into account Cattaneo-Christov heat flux model for pseudo plastic fluid on travelling surface with an equivalent free stream. Present analysis is may be beneficial in academic research in the field of heat transfer and industry.

\section{PROBLEM DEVELOPMENT}

We take boundary layer flow of an incompressible Hyperbolic Tangent Fluid over a moving surface. We consider constant velocity $u_{w}$ in the same direction as that of the uniform free stream velocity $u_{\infty}$. It is assumed that the wall and free stream temperatures $T_{w}$ and $T_{\infty}$ are constants with $T_{w}>T_{\infty}$. The geometry of present physical flow phenomena is presented in figure 1 .

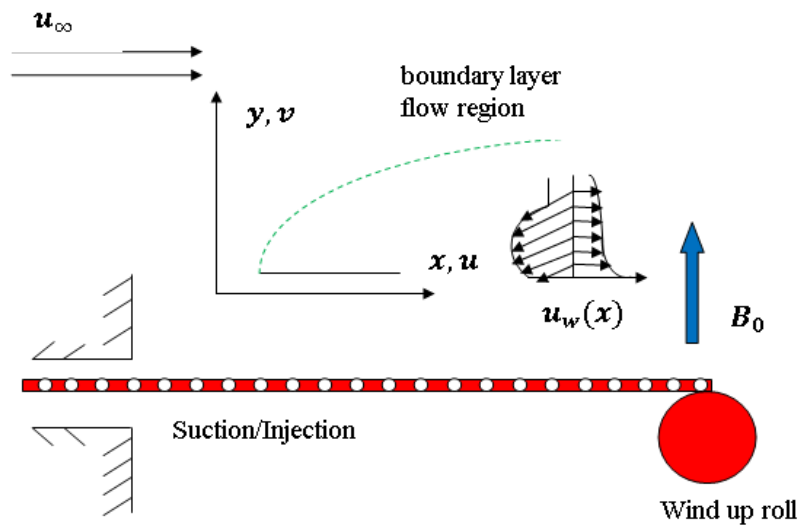

Fig. 1 Engineering Flow Diagram

Assume that a uniform magnetic field of strength $B_{0}$ is applied in the positive $y$-direction normal to the plate, and the induced magnetic field due to the magnetic Reynolds number is taken to be small enough and assumed to be negligible in comparison to the applied magnetic field. The boundary layer equations governing the flow for hyperbolic tangent fluid are

$\frac{\partial u}{\partial x}+\frac{\partial v}{\partial y}=0$

$u \frac{\partial u}{\partial x}+v \frac{\partial u}{\partial y}=v(1-n) \frac{\partial^{2} u}{\partial y^{2}}+\sqrt{2} v n \Gamma\left(\frac{\partial u}{\partial x} \frac{\partial^{2} u}{\partial y^{2}}\right)-\frac{\sigma B_{0}^{2}}{\rho} u$,

subject to flow boundary conditions

$u=u_{w}(x), \quad v=v_{w}$ at $y=0$,

$u \rightarrow u_{\infty}(x), \quad u_{y} \rightarrow 0$ as $y \rightarrow \infty$.

Where $u$ and $v$ are the velocity components along $x$ and $y$ directions, respectively. $\rho$ is density of fluid andvis kinematic viscosity. Expression for Cattaneo-Christov heat flux model discussed by (2009) is

$q+\Lambda\left(\frac{\partial q}{\partial t}+V . \nabla q-q . \nabla V-(\nabla . V) q\right)=-k \nabla T$,

in which $q$ is heat flux, $\Lambda$ is relaxation time of heat flux, $T$ is temperature, $k$ is thermal conductivity and $V$ is the velocity vector. In view of above expression temperature profile governs following relation

$$
\begin{aligned}
& u \frac{\partial T}{\partial x}+v \frac{\partial T}{\partial y}+\Lambda\left(u \frac{\partial u}{\partial x} \frac{\partial T}{\partial x}+v \frac{\partial v}{\partial y} \frac{\partial T}{\partial y}+u \frac{\partial v}{\partial x} \frac{\partial T}{\partial y}\right) \\
& \left.\left.+v \frac{\partial u}{\partial y} \frac{\partial T}{\partial x}+2 u v \frac{\partial^{2} T}{\partial x \partial y}+u^{2} \frac{\partial^{2} T}{\partial x^{2}}+v^{2} \frac{\partial^{2} T}{\partial y^{2}}\right)=\alpha \frac{\partial^{2} T}{\partial y^{2}}\right),
\end{aligned}
$$

associated boundary conditions are

$T=T_{w}(x)$ at $y=0 ; \quad T \rightarrow T_{\infty}$ as $y \rightarrow \infty$.

Here $\alpha$ is thermal diffusivity, $T_{w}$ is temperature at the wall, and $T_{\infty}$ is the ambient fluid temperature. We introduce following dimensionless quantities

$$
\begin{aligned}
& u=U f^{\prime}(\eta), \quad v=-\frac{1}{2} \sqrt{\frac{U \nu}{x}}\left[f(\eta)-\eta f^{\prime}(\eta)\right], \quad \eta=y \sqrt{\frac{U}{x \nu}}, \\
& \theta(\eta)=\frac{T-T_{\infty}}{T_{w}-T_{\infty}},
\end{aligned}
$$

in which $U=u_{w}+u_{\infty}$. Invoking above mathematical relations into Eq. (1) which is identically satisfied and Eqs. (2), (3), (5) and (6) are reduced to

$$
\begin{aligned}
& (1-n) f^{\prime \prime \prime}+\frac{1}{2} f f^{\prime \prime}-\sqrt{2} n W e f^{\prime \prime} f^{\prime \prime \prime}-M^{2} f^{\prime}=0, \\
& \theta^{\prime \prime}+\frac{1}{2} \operatorname{Pr} f \theta^{\prime}-\frac{\operatorname{Pr} \gamma}{4}\left(3 f f^{\prime} \theta^{\prime}+f^{2} \theta^{\prime \prime}\right)=0, \\
& f^{\prime}(\eta)=\lambda, \quad f(\eta)=S, \quad \theta(\eta)=1 \text { at } \eta=0, \\
& f^{\prime}(\eta)=1-\lambda, \quad \theta(\eta)=0 \text { as } \eta \rightarrow \infty .
\end{aligned}
$$

where $f(0)=S$ with $S<0$ corresponds to suction case and $S>0$ implies injection, $\lambda$ is a constant parameter, $\operatorname{Pr}$ is Prandtl number, $W e$ is Weissenberg number and $\gamma$ is the Deborah number with respect to heat flux. Definitions of these physical parameters are

$\lambda=\frac{u_{w}}{U}, \quad \operatorname{Pr}=\frac{v}{\alpha}, \quad, \gamma=\frac{\Lambda U}{x}, \quad W_{e}=\sqrt{\frac{U}{v x}} U \Gamma, \quad S=-\left(\sqrt{\frac{2 x}{v U}}\right) v_{w}$.

It is worth mentioning here that $\lambda=0$ corresponds to the flow over a stationary surface caused by the free stream velocity (Blasius flow). Whereas $\lambda=1$ corresponds to moving plate in fluid (Sakaidis flow). The case $0<\lambda<1$ is when plate and fluid are moving in same direction. If $\lambda>1$, free stream is directed toward negative $x$ - direction whereas plate moves toward positive $x$ - direction.

Skin friction coefficient $C_{f}$ is defined as

$C_{f}=\frac{\tau_{w}}{\rho u_{w}^{2}}$,

in which expressions of wall skin friction $\left(\tau_{w}\right)$ is defined by

$\tau_{w}=(1-n) \frac{\partial u}{\partial y}+\left.\frac{n \Gamma}{\sqrt{2}} \frac{\partial^{2} u}{\partial y^{2}}\right|_{y=0}$,

With the help of dimensionless variables (7) we have

$$
C_{f}\left(\operatorname{Re}_{x}\right)^{-1 / 2}=(1-n) f^{\prime \prime}(\eta)+\left.\frac{n}{2} W_{e}\left(f^{\prime \prime}(\eta)\right)^{2}\right|_{\eta=0} \text {. }
$$

where $\operatorname{Re}_{x}=U x / v$ is the local Reynolds number. 


\section{COMPUTATIONAL PROCEDURE}

Solution of Eqs. (8) and (9) subject to boundary conditions (10) by using shooting method with fifth order RK procedure. Initially using the similarity transform we get a system of nonlinear ordinary differential equation then we convert higher order nonlinear ordinary differential equations into system of first order ordinary differential equation by making suitable substitution in the form $\left(y_{1}, y_{2}, y_{3}, y_{4}, y_{5}\right)=\left(f, f^{\prime}, f^{\prime \prime}, \theta, \theta^{\prime}\right)$, this yield following mathematical relations

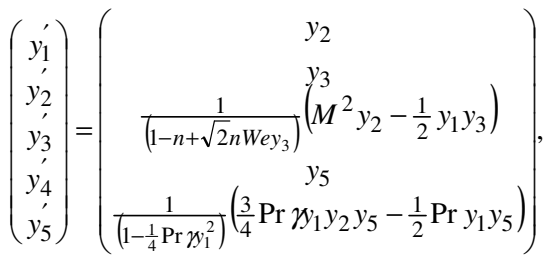

$$
\left(\begin{array}{c}
y_{1}(0) \\
y_{2}(0) \\
y_{3}(0) \\
y_{4}(0) \\
y_{5}(0)
\end{array}\right)=\left(\begin{array}{c}
S \\
\lambda \\
f^{\prime \prime}(0) \\
1 \\
\theta^{\prime}(0)
\end{array}\right) \text {. }
$$

For shooting method we implemented Newton-Raphson method to find the targets and Runge-Kutta of order 5 method is chosen for the time integration in MATLAB. A step size of 0.001 is selected satisfactory for a convergence criterion of $10^{-6}$ in nearly all cases.

\section{ANALYSIS AND DISCUSSION}

This section presents the effects of embedding parameters on the velocity and temperature fields. Figure 2-10 shows the influence of various fluid parameters on velocity profile. Figure 2 is plotted for velocity profiles for various values of $\lambda$. It is observed that velocity field decreases rapidly with an increase in $\lambda$. From the physical aspect, it is clear that an increase in plate velocity greatly reduces the velocity of fluid. The boundary layer thickness decreases by increasing $\lambda$ in the range $0 \geq \lambda<0.5$. However when $\lambda>0.5$ the boundary layer thickness grows with the increasing values of $\lambda$. Hartman number $M$ is ratio of electromagnetic force to the viscous force. Increase in the values of $\mathrm{M}$ causes a decrease in viscous forces, as a result velocity of fluid decrease and increase in boundary layer thickness. This trend can be depicted in figure 3 for Sakaidis flow. For $(\lambda=0.2)$ Blasius flow similar behavior can be observed through figure 4 . It is also analyzed that $M$ is perpendicular to the moving surface so for rising values of Hartman number it reduces the velocity and enhances the boundary layer thickness.

The effect of power law index $n$, Weissenberg number $W e$ and Suction parameter $S$ on fluid velocity are demonstrated through figures 5, 7 and 9, respectively (Sakaidis flow $\lambda<1$ ) whereas figs. 6, 8 and 10 demonstrate Blasius flow $(\lambda<1)$ for different values of same physical parameters. Weissenberg number is the ratio of relaxation time of fluid and a specific process time. It increases thickness of the fluid, so velocity profile decreases with an increase in $W e$. The power law index menhances the fluid velocity and boundary layer thickness, while We shows an opposite trend for fluid velocity. The impact of Suction parameter $S$ also enhances velocity profile while boundary layer thickness decays in this case (see figure 10). Due to physical aspect, growth of boundary layer reduced by employing the suckling particles in the porous wall. It is quite obvious that, a suction cause reduces boundary layer thickness.

Effects of various parameter on temperature and thermal boundary layer are examined through figures 11-16 for Sakaidisflow $(\lambda=1)$. The contribution of Prandtl number Pr and Deborah number with respect to the relaxation time of heat flux $\gamma$ on the temperature field $\theta(\eta)$ can be seen in figures 11 and 12. The effect of Prandtl number $\operatorname{Pr}$ on $\theta$ can be visualized in Fig. 11. It is obvious that an increase in the values of Pr greatly reduces the thermal diffusivity, therefore temperature and the thermal boundary layer thickness are decreasing functions of Pr. It is also observed that deviation in the temperature profiles is more significant for small values of $\operatorname{Pr}$ when compared with its larger values. It is important to note that $\operatorname{Pr}(<1)$ corresponds to liquid metals which have higher thermal diffusivity. However while large values of $\operatorname{Pr}(>1)$ lead to high-viscosity oils. The impact of non-dimensional relaxation time heat flux $\gamma$ on the temperature field is analyzed in figure 12 . There is a decrease in temperature when $\dot{\epsilon}$ enhances. Temperature profile $\theta(\eta)$ in figure 13,14 and 15 are plotted against different values of power law index $n$, Weissenberg number We and Hartman number $M$, respectively. All these parameters contribute in rising in temperature profile with broadness in thermal boundary layer also observed. Viscous forces reduce for larger Hartman number $M$, as a result thermal forces increases and hence temperature of the fluid enhances (see figure 15 ). Figure 16 depict the influence of Suction parameter $S$ on temperature. Increasing suction effect tends to decrease the temperature and thermal boundary layer thickness. In accordance with the Mukhopadhyay (2009) an increase in the suction parameter $S$ corresponds to a decrease in the temperature and the thermal boundary layer thickness. Figures 17-20 are devoted to illustrate flow patterns for different values of We for Sakaidis and Blasius flows. It is depicted that flow pattern for Sakaidis flow is concave down (see Figs. 17 and 18) while it is concave up (see Fig. 19 and 20) in Blasius flow.

The numerical values of skin friction for Sakaidis flow $(\lambda=1)$ and Blasius flow $(\lambda<1)$ visualized through table 1 . In both cases $(\lambda=1)$ and $(\lambda<1)$ the rate of shear stress at wall decreases with increasing values of power law index $n$, where an increase can be observed in skin friction for higher values of $W e, M$ and $S$.

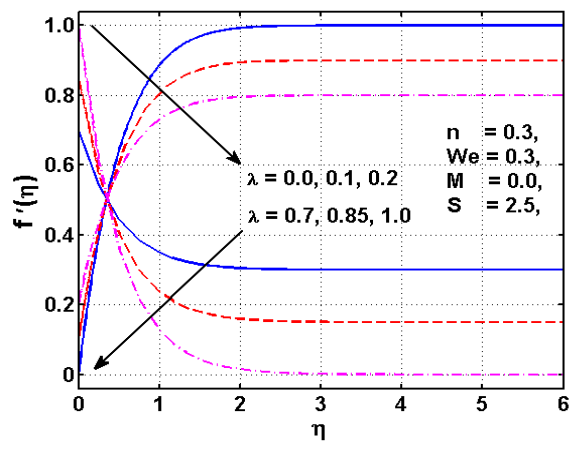

Fig. 2 Effect of $\lambda$ on $f^{\prime}(\eta)$. 


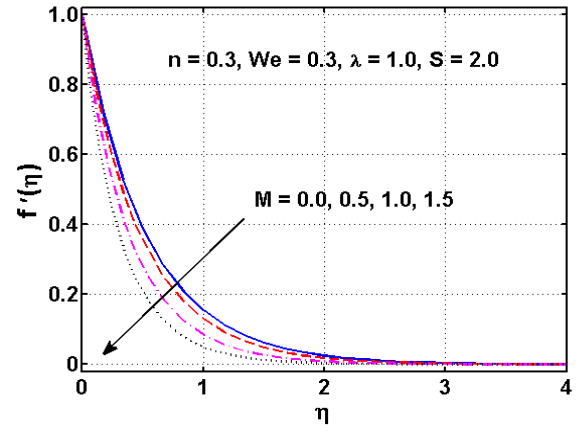

Fig. 3 Effect of $M$ on $f^{\prime}(\eta)$ for Sakaidis flow

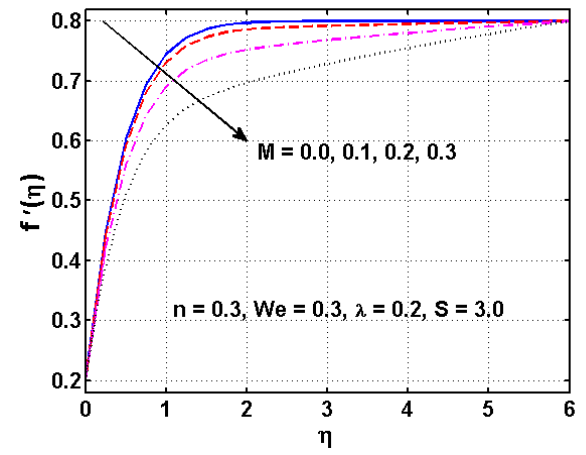

Fig. 4 Effect of $M$ on $f^{\prime}(\eta)$ for Blasius flow

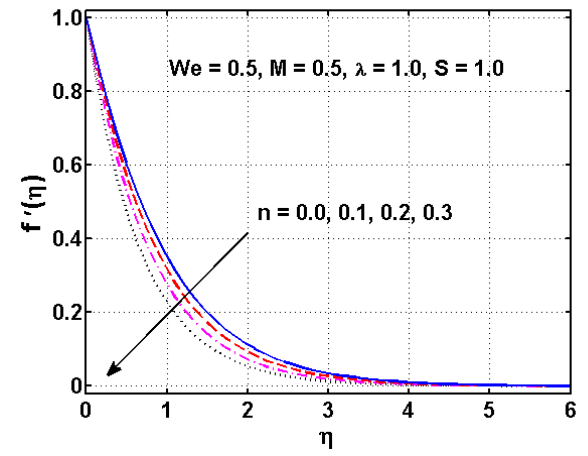

Fig. 5 Effect of $n$ on $f^{\prime}(\eta)$ for Sakaidis flow

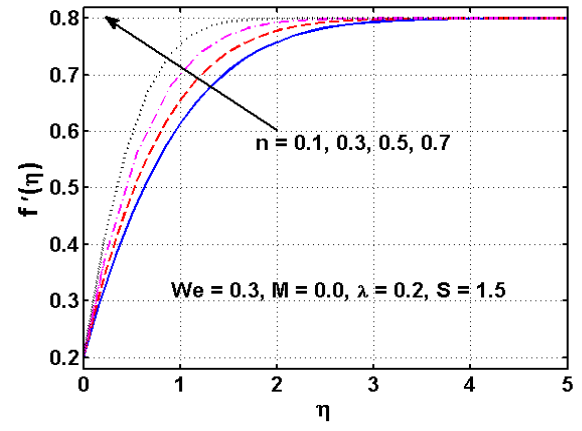

Fig. 6 Effect of $n$ on $f^{\prime}(\eta)$ for Blasius flow

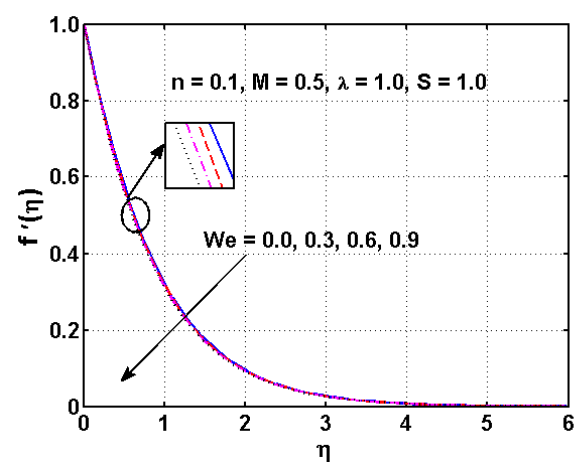

Fig. 7 Effect of We on $f^{\prime}(\eta)$ for Sakaids flow

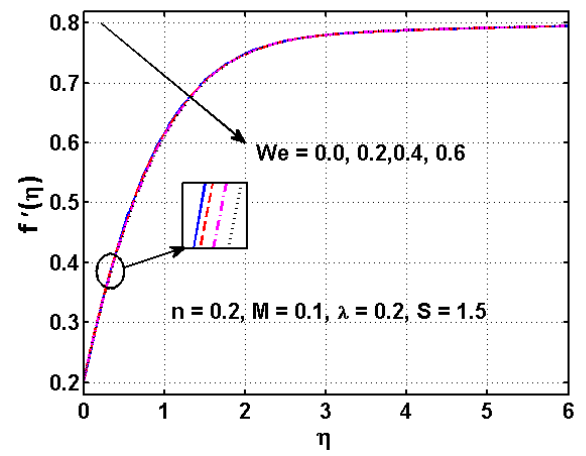

Fig. 8 Effect of We on $f^{\prime}(\eta)$ for Blasius flow

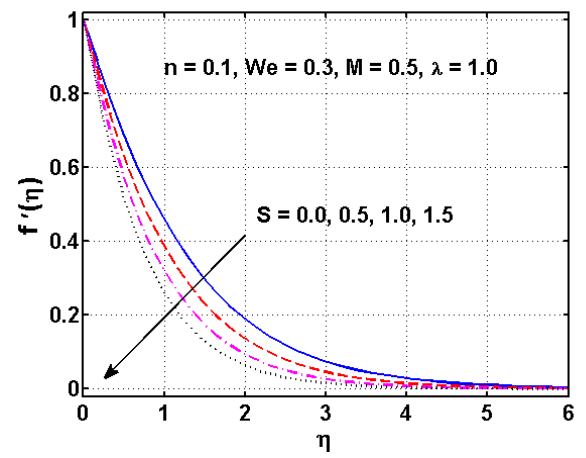

Fig. 9 Effect of $S$ on $f^{\prime}(\eta)$ for Sakaidis flow

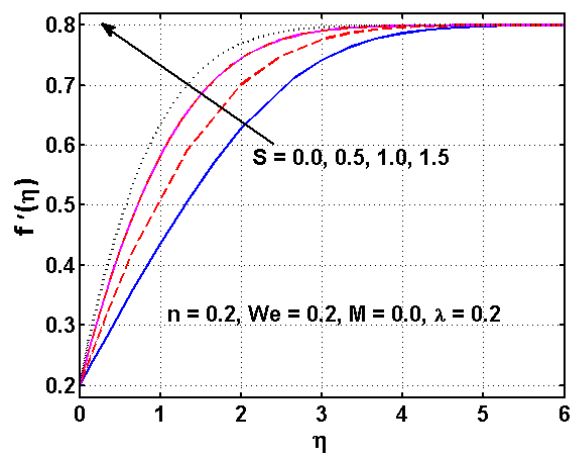

Fig. 10 Effect of $S$ on $f^{\prime}(\eta)$ for Blasius flow 


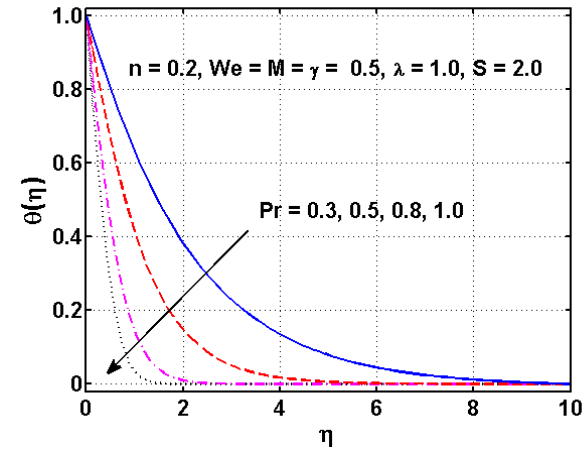

Fig. 11 Effect of $\operatorname{Pr}$ on $\theta(\eta)$

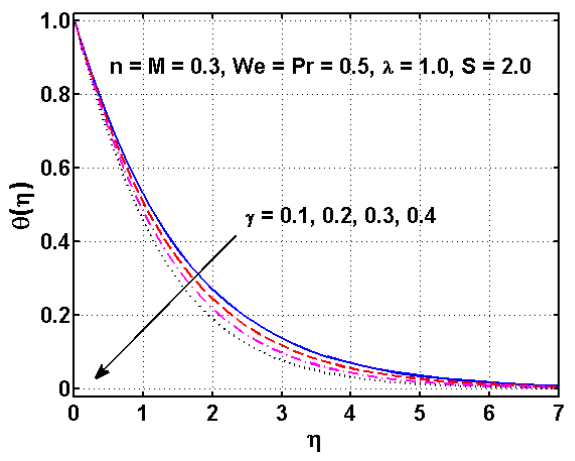

Fig. 12 Effect of $\gamma$ on $\theta(\eta)$

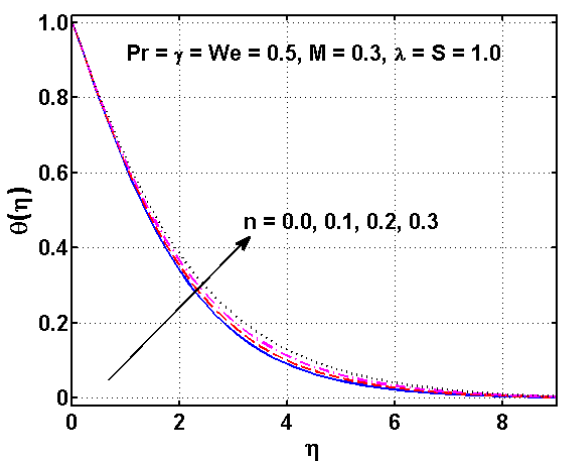

Fig. 13 Effect of $n$ on $\theta(\eta)$

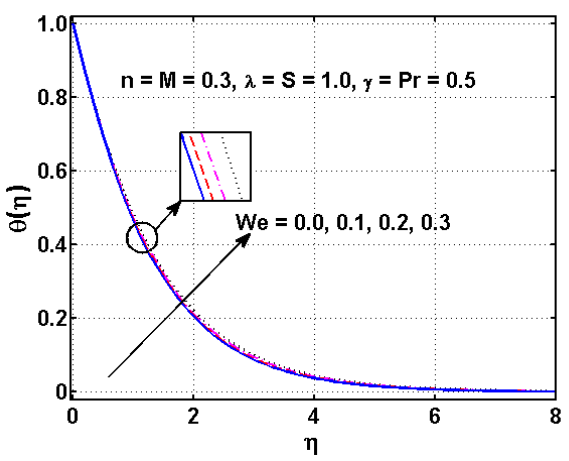

Fig. 14 Effect of We on $\theta(\eta)$

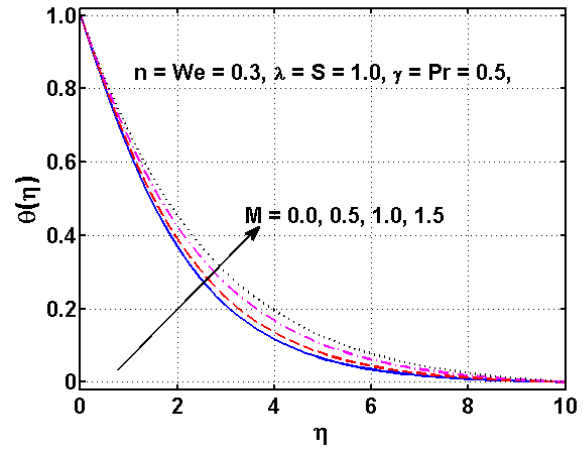

Fig. 15 Effect of $M$ on $\theta(\eta)$

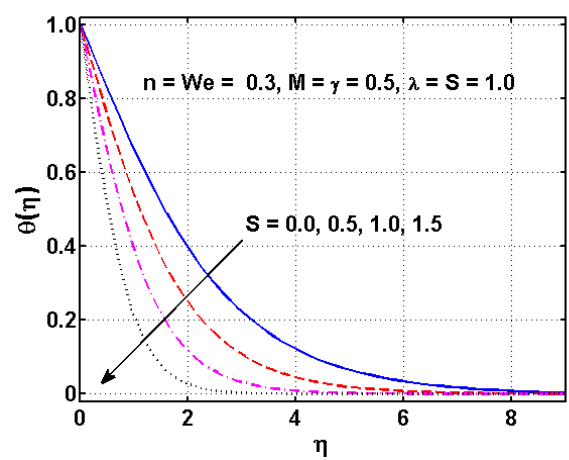

Fig. 16 Effect of $S$ on $\theta(\eta)$

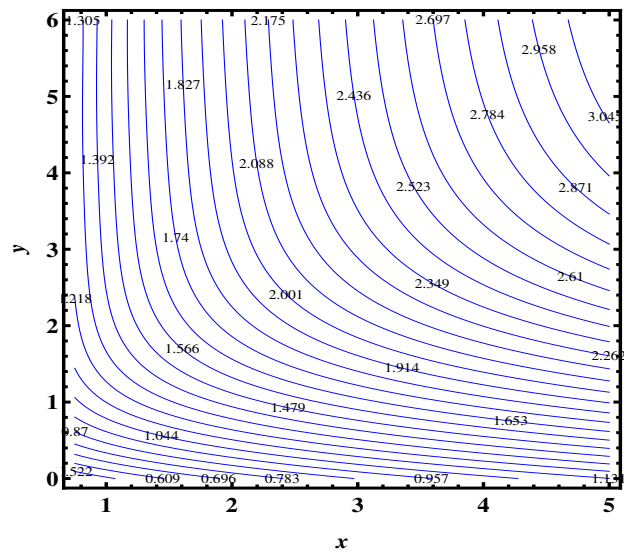

Contour Plot

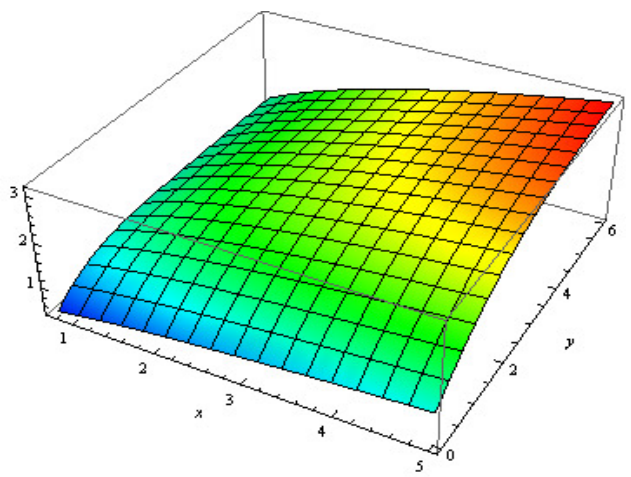

3D Plot

Fig. 17 Streamlines for Sakaidis flow when $W e=0.1$. 

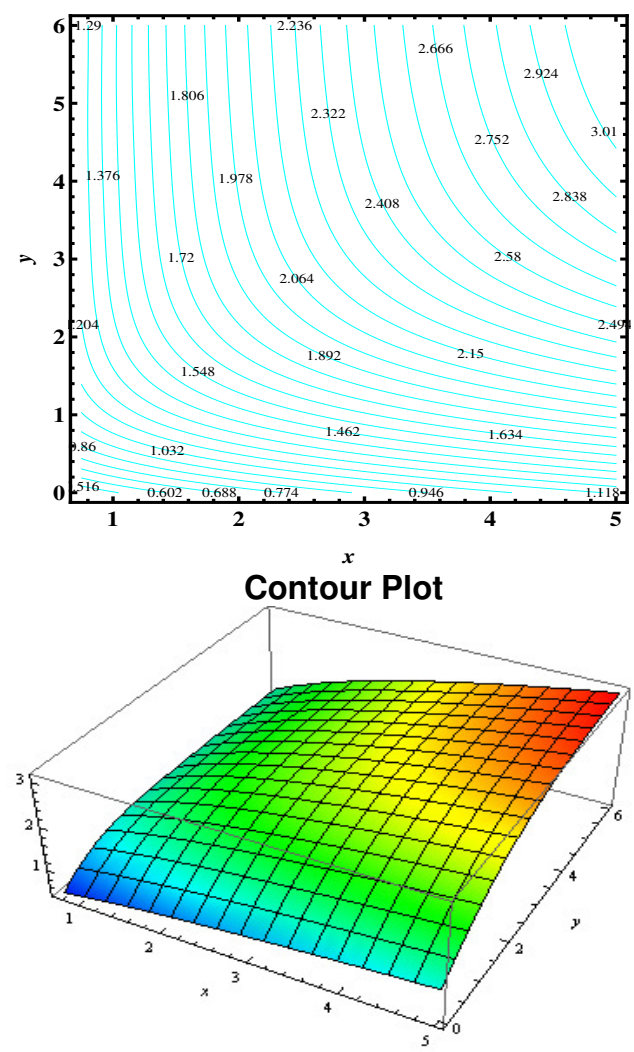

3D Plot

Fig. 18 Streamlines for Sakaidis flow when $W e=0.2$.
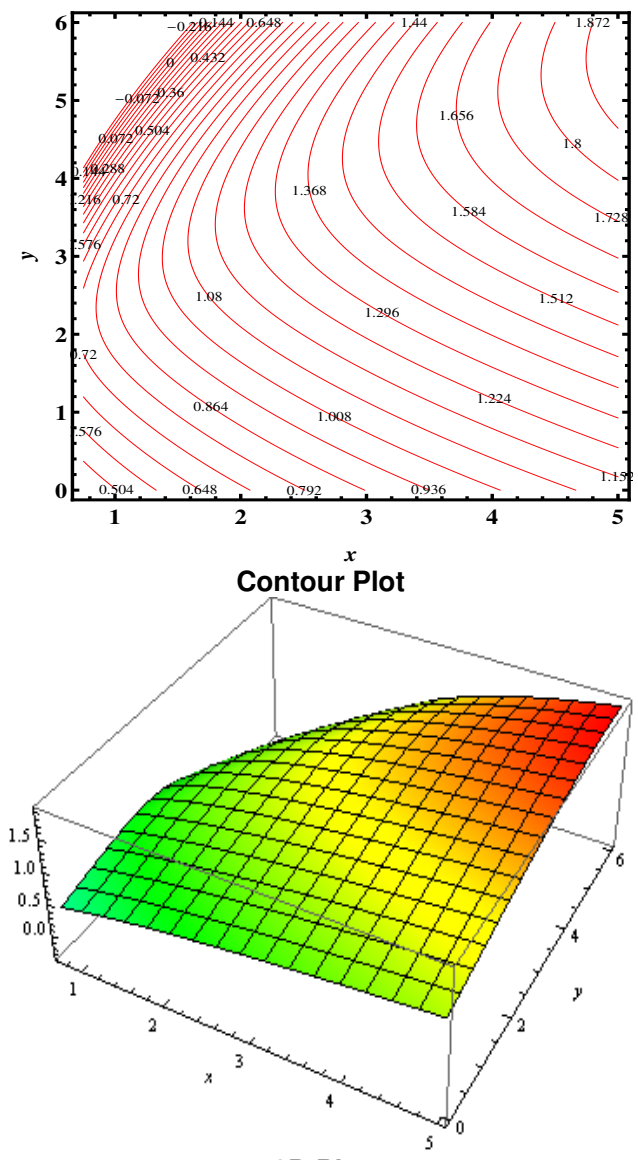

3D Plot

Fig. 19 Streamlines for Blasius flow when $W e=0.1$.

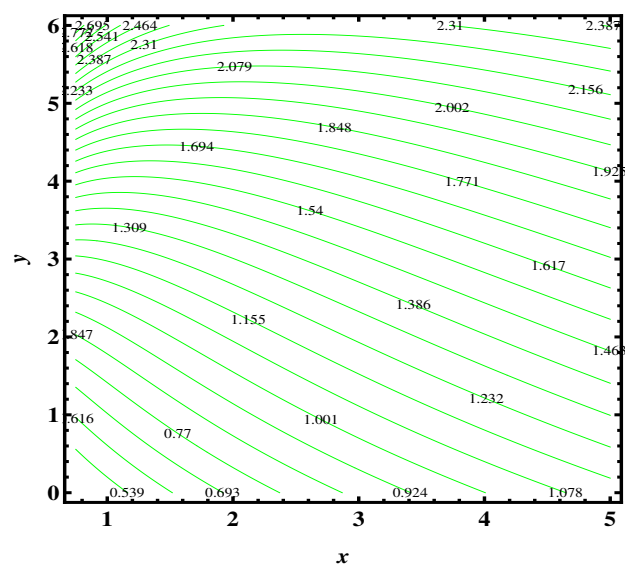

Contour Plot

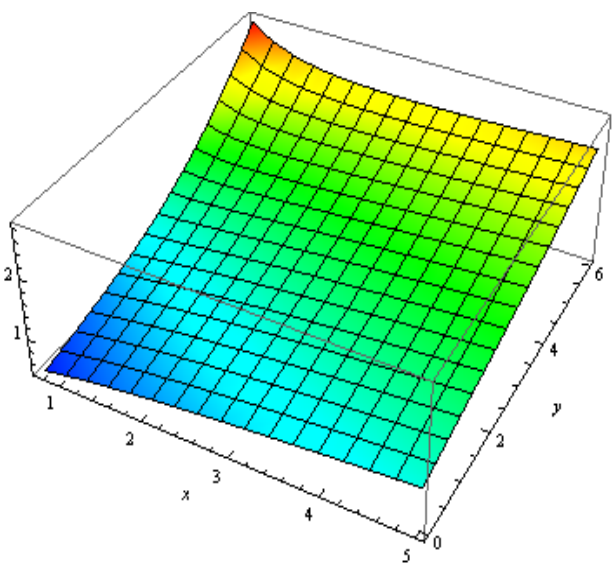

3D Plot

Fig. 20 Streamlines for Blasius flow when $W e=0.2$.

Table 1 Tabulated values of shear stress at wall for different parameters.

\begin{tabular}{|l|l|l|l|l|l|}
\hline$n$ & We & $M$ & $S$ & $\begin{array}{l}-\sqrt{\operatorname{Re}_{x}} C_{f}(\lambda-1) \\
\text { Skaidis Flow }\end{array}$ & $\begin{array}{l}-\sqrt{\operatorname{Re}_{x}} C_{f}(\lambda-2) \\
\text { Blasius Flow }\end{array}$ \\
\hline 0.1 & 0.1 & 0.5 & 0.5 & 0.7727 & 0.1091 \\
\hline 2.0 & & & & 0.7378 & 0.1074 \\
\hline 3.0 & & & & 0.7010 & 0.1052 \\
\hline 4.0 & & & & 0.6620 & 0.1022 \\
\hline 0.2 & 0.3 & & & 0.7386 & 0.1074 \\
\hline & 0.5 & & & 0.7400 & 0.1075 \\
\hline & 0.7 & & & 0.7422 & 0.1075 \\
\hline & 0.9 & & & 0.7455 & 0.1075 \\
\hline & 0.5 & 0.4 & & 0.6807 & 0.0332 \\
\hline & & 0.6 & & 0.8063 & 0.1376 \\
\hline & & 0.8 & & 0.9534 & 0.1743 \\
\hline & & 1.0 & & 1.1126 & 0.2089 \\
\hline & & 0.5 & 0.1 & 0.6140 & 0.0958 \\
\hline & & & 0.3 & 0.6750 & 0.1026 \\
\hline & & & 0.5 & 0.7400 & 0.1074 \\
\hline & & & 0.7 & 0.8091 & 0.1096 \\
\hline
\end{tabular}

\section{CLOSING REMARKS}

From the above study we conclude the following findings:

- Boundary layer thickness trend was observed to be opposite to boundary each other for Blasius and Sakaidis flow. 
- Hartman number $M$ and fluid parameter Weissenberg number We shows a decrease in velocity profile and boundary layer thickness for both type of flows.

- Boundary layer thickness enhances by increasing power law index $n$ and Suction parameter $S$ for the case of Blasius flow, opposite to Sakaidis flow.

- Dwindle of thermal boundary layer is witness for rising values of $\gamma$, Pr and $S$ while augmented boundary layer is observed for increasing values of $n, M$ and fluid parameter.

- Power law index $n$ lessen skin friction for Sakaidis and Blasius flow, while for all other pertinent parameters an increased skin friction is observed.

\section{REFERENCES}

Ali, L., and Vafai, K., 2005, "An Investigation of Stokes Second Problem for Non-Newtonian Fluids," Numerical Heat Transfer, Part A: Applications, 47, 955-980. http://dx.doi.org/10.1080/10407780590926390

Bachok, N., Ishak, A., and Pop I., 2010,"Boundary Layer Flow of Nanofluids over A Moving Surface in a Flowing Fluid," International Journal of Thermal Science, 49, 1663-1668.

http://doi.org/10.1016/j.ijthermalsci.2010.01.026

Blasius, H., 1908, "Grenzschichten in Flussigkeitenmitkleiner Reibung," Zeitschriftfürangewandte Mathematik und Physik, 56, 1-41.

Cattaneo, C., 1948, "Sullaconduzion edelcalore, in: Atti del Seminario Matematico e Fisico dell Universita di Modena e Reggio Emilia," 3, 83101.

Christov, C.I., 2008, "On Frame in Different Formulation of the Maxwell--Cattaneo Model of Finite-Speed Heat Conduction," Mechanics Research Communication, 36, 481-486.

http://dx. doi:10.1016/j.mechrescom.2008.11.003

Elliott, J.W., and Smith,F.T., 1983,"'Breakdown of Boundary Layers: (i) on Moving Surface; (ii) in Semi-Similar Unsteady Flow; (iii) in Fully Unsteady Flow," Geophysical \& Astrophysical Fluid Dynamics, 25, 77138.

http://dx.doi.org/10.1080/03091928308221749

Fourier, J.B.J., 1822, "Theorie Analytique De La Chaleur, Chez FirminDidot, Paris".

Grosan,T.S., Pop, I., and Na,T.Y., 2000,"Similarity Solutions for Boundary Layer Flows on a Moving Surface in Non-Newtonian Power Law Fluids," Technische Mechanik, 1, 41-50.

Han, S., Zheng, I., Li, C., and Zhang, X., 2014, "Coupled Flow and Heat Transfer in Visco Elastic Fluid With Cattaneo-Chirstov Heat Flux Model," App. Math. Lett., 38, 87-93.

http://dx.doi.org/10.1016/j.aml.2014.07.013

Harfoush, F.,Taflove, A., and Kroegsmann,G.A.,1989, “A Numerical Technique for Analyzing Electromagnetic Wave Scattering from Moving Surface in One and Two Dimensions," IEEE Transactions on Antennas and Propagation, 37, 55-63.

http://dx.doi: 10.1109/8.192164
Khan, J.A., Mustafa, M., Hayat, T. and Alsaedi, A., 2015, "Numerical Study of Cattaneo-christov Heat Flux Model for Visco Elastic Flow Due To an Exponentially Stretching Surface," PLoS One, 10, 1-10.

https://doi.org/10.1371/journal.pone.0137363

Li, J., Zheng, L. and Liu, L., 2016, "MHD Viscoelastic Flow and Heat Transfer over a Vertical Stretching Sheet with Cattaneo-Christov Heat Flux Effects," Journal of Mol. Liq., 221, 19-25. http://doi.org/10.1016/i.molliq.2016.05.051

Liu, L., Zheng, L., Liu, F. and Zhang, X., 2017, "Heat Conduction with Fractional Cattaneo-Christov Upper-Convective Derivative Flux Model," Int. Therm. Sci., 112, 421-426.

http://doi.org/10.1016/j.ijthermalsci.2016.11.008

Muhammad, N., Nadeem, S. and Mustafa, T., 2017, "Squeezed Flow of a Nanofluid with Cattaneo-Christov Heat and Mass Fluxes," Res. Phy., 7, 862-869.

http://doi.org/10.1016/j.rinp.2016.12.028

Muhammad, N., Nadeem, S. and Haq, R.U., 2017, "Heat Transport Phenomenon in the Ferromagnetic Fluid over a Stretching Sheet with Thermal Stratification," Res. Phy., 7, 854-861.

http://doi.org/10.1016/j.rinp.2016.12.027

Mukhopadhyay, S., 2009, "Effect of Thermal Radiation on Unsteady Mixed Convection Flow and Heat Transfer over a Stretching Surface in a Porous Medium," International Journal of Heat and Mass Transfer, 52, 3261-3265.

http://doi.org/10.1016/j.ijheatmasstransfer.2008.12.029

Nadeem, S. and Muhammad, N., 2016, "Impact of Stratification and Cattaneo-Christov Heat Flux in the Flow Saturated with Porous Medium," J. Mol. Liq., 224, 423-430.

http://doi.org/10.1016/j.molliq.2016.10.006

Pop, I. and Gorla, R.S.R., 1990, "Second Order Boundary Layer Solution for a Continuous Moving Surface in a Non-Newtonian Fluid," International Journal of Engineering Science, 28, 313-322. https://doi.org/10.1016/0020-7225(90)90104-Q

Pop, I.,and Watanabe, T.,1992, “The Effects of Suction or Injection in Boundary Layer Flow and Heat Transfer on a Continuously Moving Surface," Technische Mechanik, 13, 49-54.

Sakiadis, B.C., 1961,'Boundary Layer Cattaneo-Christov Doublediffusion Model of Heat and Mass Transfer in Upper-Convected Maxwell Nanofluid Past a Stretching Sheet with Slip Velocity," American Institute of Chemical Engineers Journal, 7, 26-28.

http://dx.doi: 10.1002/aic.690070108

Sui, J., Zheng, L. and Zhang, X., 2016, "Boundary Layer CattaneoChristov Double-Diffusion Model of Heat And Mass Transfer in Upper-convected Maxwell Nanofluid Past a Stretching Sheet with Slip Velocity," Int. Therm. Sci., 104, 461-468.

http://doi.org/10.1016/j.ijthermalsci.2016.02.007

Tibullo, V. and Zampoli, V., 2011, "A Uniqueness Result for the Cattaneo-Christov Heat Conduction Model Applied to Incompressible Fluids," Mech. Res. Comm., 38, 77-79.

http://doi.org/10.1016/j.mechrescom.2010.10.008

Weidman, P.D. , Kubitschek, D.G., and Davis,A.M.J.,2006,” The Effect of Transpiration on Self-Similar Boundary Layer over Moving Surfaces," International Journal of Engineering Science, 44, 730-737. http://doi.org/10.1016/j.ijengsci.2006.04.005 